\title{
SOBRE A EQUIDADE E OUTROS IMPACTOS DOS INCENTIVOS MONETÁRIOS PARA PROFESSORES
}

NIGEL BROOKE

\section{RESUMO}

$\mathrm{Na}$ educação, as políticas de responsabilização costumam gerar polêmica, sobretudo quando fundamentadas em medidas que criam consequências significativas para os professores e suas escolas. Em existência no Brasil por mais de uma década, o pagamento de bonificação anual à equipe escolar com base no nível de desempenho médio dos alunos em avaliações externas é o exemplo mais difundido no nosso meio de política de responsabilização high stakes. Entre as diversas críticas ao uso desse tipo de incentivo, encontra-se o temor que a política leve a desigualdades sistêmicas ainda maiores por incentivar os melhores professores a procurarem as escolas com alunos de nível socioeconômico mais alto. 0 artigo mostra que as consequências das políticas de incentivos dependem do seu desenho, e que com metodologias apropriadas é possível combater as desigualdades sociais do sistema.

PALAVRAS-CHAVE RESPONSABILIZAÇÃO • BONIFICAÇÃO • EQUIDADE. 


\section{RESUMEN}

En educación, las políticas de responsabilización suelen provocar polémica, sobre todo cuando están fundamentadas en medidas que generan consecuencias significativas para los docentes y sus escuelas. En Brasil, desde hace más de una década, se paga una bonificación anual al equipo escolar, basada en el nivel de rendimiento promedio de los alumnos en evaluaciones externas. Este es el ejemplo más difundido en nuestro medio de una política de responsabilización high stakes. Entre las diversas críticas al uso de este tipo de incentivo, se encuentra el temor de que la política lleve a desigualdades sistémicas todavía mayores por incentivar a los mejores profesores a buscar escuelas con alumnos de nivel socioeconómico más alto. El artículo muestra que las consecuencias de las políticas de incentivos dependen de su diagramación, y que con metodologías apropiadas es posible combatir las desigualdades sociales del sistema.

PALABRAS CLAVE RESPONSABILIZACIÓN • BONIFICACIÓN • EQUIDAD.

\section{ABSTRACT}

In education, accountability policies often generate controversy, especially when they are based on measures that create significant consequences for teachers and their schools. In existence in Brazil for more than a decade, the payment of annual bonuses to school staff based on average student performance by external evaluation standards is the most widespread example among us of high stakes accountability policy. Among the many criticisms regarding the use of this type of incentive is the fear that the policy will lead to even greater systemic inequalities by encouraging the best teachers to seek schools with students of a higher socioeconomic level. This article shows that the consequences of incentive policies depend on their design, and that with appropriate methodologies it is possible to curb the system's social inequalities.

KEYWORDS ACCOUNTABILITY • BONUS・EQUITY. 


\section{INTRODUÇÃO}

Em artigo recente (BROOKE; CUNHA, 2011), foi descrito um sistema classificatório para as diversas políticas educacionais dos governos estaduais, que de uma forma ou outra, fazem uso dos resultados gerados pelos seus próprios sistemas de avaliação externa. O sistema classificatório tornou-se necessário para descrever adequadamente a grande variedade de políticas encontradas em pesquisa realizada em 2010. Diferentemente de pesquisa similar anterior, que em 2006 concluiu que a utilização dos resultados pelos governos estaduais para subsidiar políticas educacionais ainda era escassa (SOUSA; OLIVEIRA, 2007), nossa pesquisa encontrou um alto grau de experimentação com diversos instrumentos de gestão calcados nos resultados de aprendizagem dos alunos. Foi essa diversidade que exigiu a criação de uma tipologia que servisse para organizar a discussão sobre a avaliação como instrumento de gestão e para monitorar as mudanças aceleradas nesta esfera da política educacional. A tipologia foi denominada de "Classificação dos Usos da Avaliação Externa como Instrumento da Gestão Educacional”. 
A diferença básica entre o sistema classificatório apresentado e sistemas similares de outros autores (SHULHA; COUSIN, 1997; SOARES, 2002; DANTAS, 2009) reside na bidimensionalidade da matriz, que além de classificar a política pelo seu objetivo operacional também qualifica o nível de responsabilização inerente à política. Nessa dimensão da matriz, distinguem-se entre as políticas de responsabilização, as políticas low stakes, em que as consequências dos resultados são mais simbólicas e, por serem difusas, pouco afetam a vida dos atores individuais; e as políticas high stakes, em que as consequências são significativas para o indivíduo ou sua instituição, em termos funcionais e/ou econômicos. ${ }^{1}$ No caso brasileiro, as políticas high stakes quase sempre atingem os professores e suas escolas, havendo só um exemplo do uso de resultados de sistemas de avaliação externa para determinar a classificação ou promoção de alunos. ${ }^{2}$

Entre as políticas high stakes encontram-se as políticas de incentivos monetários. ${ }^{3}$ Chamadas em outros países de pagamento por resultados, incentivos de desempenho ou remuneração variável, essas políticas abrangem o que aqui são chamados de sistemas de bonificação ou premiação, projetados para calcular e conceder um adicional, eventual, à remuneração dos profissionais da educação. No Brasil, essas políticas são de diferentes tipos, aplicadas com metodologias e periodicidades distintas e com níveis variados de abrangência e premiação, mas todas coincidem em propor uma remuneração variável adicional para os professores que, no seu cálculo, leva em consideração o nível de desempenho alcançado pelos alunos da escola em uma ou mais avaliações externas. Mesmo empregando metodologias diversas, as premissas dos diferentes sistemas de bonificação são essencialmente as mesmas: existe uma relação entre o desempenho dos profissionais da educação (principalmente os professores) e a aprendizagem dos alunos; uma forma de aumentar o desempenho desses profissionais é oferecer um bônus ou prêmio relacionado ao nível de aprendizagem dos alunos, funcionando como um incentivo ou como reconhecimento pelos bons resultados do exercício da docência. O bônus contribui para a melhoria da qualidade da educação
1 Ver Brooke (2006, 2008) para definição mais ampla da responsabilização como política educacional e dos termos high stakes e low stakes.

2 Em 2001, a Secretaria de Educação de São Paulo empregou os resultados do Saresp da 4⿳亠丷a e 8a séries para determinar a promoção ou retenção dos alunos. A experiência foi amplamente criticada pelo fato dos alunos não saberem de antemão que seus resultados seriam usados para essa finalidade e pelo fato da Secretaria ter se baseado em informações geradas por instrumentos não desenhados para a tomada de decisões individuais.

3 Em outras ocasiões usei o termo "incentivos salariais". Mesmo quando o bônus é calculado como proporção do salário do professor, o termo é incorreto por sugerir um aumento permanente na remuneração. 
4 Para uma descrição da história das políticas estaduais de incentivos, ver Brooke (2011) definida em termos da aprendizagem dos alunos. Em outras palavras, o bônus é um reconhecimento justo pelo bom desempenho dos professores e de outros profissionais, que também possa servir de incentivo para melhorias futuras no nível de aprendizagem dos alunos. Na maioria das vezes não fica explicitada se a melhoria no desempenho dos professores viria por esforços individuais ou coletivos adicionais, ou por melhorias no nível de competência docente. Na ausência de modalidades de formação em serviços atrelados especificamente à política de incentivos, deve-se supor que o impacto esperado seja consequência de níveis motivacionais mais elevados.

A experiência brasileira com políticas de incentivo monetário para professores é de mais de uma década. A virulência da reação dos docentes tem variado de estado para estado. ${ }^{4}$ No Ceará, as políticas de premiação têm sido assimiladas após constantes ajustes nas regras de distribuição para eliminar aparentes injustiças. Em outros lugares, como no Rio de Janeiro e em São Paulo, as mesmas políticas têm incitado intensa polêmica, levando, no primeiro caso, ao encerramento da política, e, no segundo, à reformulação da sua metodologia. Apesar das intensas discussões públicas, o caráter predominantemente doutrinário das críticas tem impedido pesquisas mais pormenorizadas sobre as metodologias usadas e as consequências reais dos incentivos. A rejeição quase integral da política se deve a suas origens neoliberais (HIDAKA, 2011), seu desrespeito pelo princípio da isonomia salarial e sua associação com a filosofia política da meritocracia que, pelas suas conotações competitivas, é tomada como antítese do desenvolvimento de um sistema educacional democrático, fundamentado na colaboração (D’ELBOUX, 2011).

Apesar do ambiente ideologicamente carregado, algumas das discussões veiculadas na imprensa e em documentos de circulação nacional oferecem argumentos a respeito das possíveis consequências indesejáveis das políticas de incentivos na distribuição e qualidade do ensino. Nesses casos, as críticas são fundamentadas em hipóteses relativas ao funcionamento do sistema e abrem espaço para um diálogo com 
os responsáveis pela implantação das políticas de incentivos. Pelo uso de argumentos sobre os possíveis efeitos negativos dessas políticas na qualidade do ensino, o raciocínio empregado permite uma discussão com base em evidências, produzidas por pesquisas, e a possibilidade de se chegar a uma conclusão independente sobre o impacto da política. É nesse espaço que proponho situar a minha discussão sobre as evidências disponíveis.

\section{BONIFICAÇÃO E EQUIDADE}

Em artigos publicados no jornal 0 Estado de São Paulo, em 2010, e na Folha de São Paulo, em 2012, Maria Alice Setubal, presidente do Centro de Estudos e Pesquisas em Educação, Cultura e Ação Comunitária (Cenpec), levanta a tese de que, nos moldes atuais, o pagamento de bônus pode criar uma concorrência pouco saudável entre as escolas e provocar desigualdades ainda maiores que as já existentes. O raciocínio é claro: os professores concursados, em condições de escolher seu lugar de trabalho, procurarão as escolas com melhores resultados para aumentar suas chances de receberem o bônus. Essas escolas são as que têm alunos de nível cultural mais elevado. Em consequência, as que são de periferia, com clientelas de alta vulnerabilidade, serão deixadas para os professores não concursados, de menor capacidade. A autora acredita que o movimento deveria ser o contrário, por meio de políticas de incentivos monetários, para levar os melhores professores para as escolas de periferia e, desse modo, contribuir para a diminuição da desigualdade. Ou seja, usar a meritocracia no contexto de uma política de equidade, a favor da periferia e não contra ela.

A crítica considera o sistema de bonificação de 2012 do Estado de São Paulo como padrão para a política de incentivos monetários. ${ }^{5}$ Se tivesse considerado como modelo a política atual do Estado do Espírito Santo, por exemplo, a discussão certamente seria outra. No caso desse estado, o cálculo do bônus é feito com base em um Indicador de Desenvolvimento da Escola (IDE), que leva em consideração o nível

5 Segundo notícia no portal do Todos pela Educação, em 18/04/2012, a política de bonificação dos profissionais da rede estadual de educação do Estado de São Paulo mudará a partir de 2013 para incluir critérios socioeconômicos dos estudantes e da região onde a escola está localizada. Disponivel em: <http:// www.todospelaeducacao.org.br/ comunicacao-e-midia/educacao-namidia/22338/bonus-muda-em-2013diz-secretario-de-educacao-de-sp>. Acesso em: dez. 2012. 
socioeconômico dos alunos. Dessa forma, a bonificação pode ser distribuída tanto para escolas de periferia quanto para escolas com clientelas mais privilegiadas. Mais concretamente, o IDE é função dos resultados da escola, calculado com base no percentual de alunos em cada faixa de desempenho em todos os diferentes testes aplicados ao longo do período de referência de dois anos ou mais, multiplicado pelo indicador de esforço da escola. Esse indicador, que tenta fazer uma equalização do nível de dificuldade da clientela, em termos do esforço necessário por parte dos docentes, fundamenta-se em dois critérios: o nível socioeconômico dos alunos da escola, com base nos dados sobre a renda, ocupação e escolaridade dos pais, coletados pelos instrumentos contextuais do Programa de Avaliação da Educação Básica do Espírito Santo (Paebes), e a série dos alunos testados. Para o primeiro critério, leva-se em consideração a conhecida relação entre a condição socioeconômica dos alunos e seu rendimento em testes de desempenho. Para o segundo critério, estima-se ser mais difícil trabalhar com alunos do primeiro ano do ensino médio, que já têm uma história longa de não aprendizagem, do que com alunos que acabaram de entrar no sistema. Em consequência, o esforço recebe ponderações cada vez maiores na medida em que os alunos vão avançando dentro do sistema (ESPÍRITO SANTO, 2010).

Para evitar um possível ranqueamento das escolas, que, mesmo não refletindo diferenças socioeconômicas, poderia contribuir para o tipo de movimentação de professores, na direção temida por Maria Alice Setubal, a Secretaria desistiu de fixar o valor da bonificação de forma linear de acordo com o valor do IDE da escola. Em seu lugar, criou 11 classes de desempenho que abrangem faixas iguais na variação total do IDE, mas que congregam um número variável de escolas. Dentro de cada classe, portanto, não há diferença entre as escolas no valor da bonificação recebida. De acordo com a classe, as escolas ganham de $33 \%$ a $100 \%$ do valor do bônus estipulado a cada ano.

Em princípio, poderiam ser acrescidos ao modelo de cálculo do bônus diversos outros indicadores de esforço da escola como a relação professor/aluno, o tamanho da escola 
e a localização geográfica. A política de incentivos monetários também comportaria os mecanismos de ação positiva cogitados por Maria Alice. Havendo a determinação política, seria perfeitamente possível privilegiar as escolas com níveis socioeconômicos mais baixos com índices de esforço ainda maiores de modo a incentivar os professores a pedirem transferência para a periferia. Os limites dessa inovação seriam dados pela capacidade da Secretaria de dar uma explicação compreensível para os critérios empregados, de estabelecer um nível de bonificação capaz de servir de incentivo e, mais difícil, de certificar que os professores que aceitam o incentivo sejam os que mais têm a contribuir para a melhoria da qualidade do ensino nas escolas da periferia. Do ponto de vista dos alunos, os custos da movimentação em termos da rotatividade de professores seriam temporários, mas os ganhos, em termos de equidade, permanentes.

A criação de mecanismos de compensação pelo nível socioeconômico dos alunos, junto com outros indicadores do esforço da escola, não é a maneira mais exata de levar em consideração as condições específicas em que a escola trabalha. Para evitar o risco de aprofundar desigualdades preexistentes com um sistema de bonificação que premia as escolas com clientelas de nível socioeconômico mais alto, existe a alternativa de levar em consideração o ponto de partida dos alunos e, em vez de aferir a média de desempenho dos alunos em algum momento no tempo, calcular o valor agregado pela escola ao longo de determinado período. Com esse cálculo, que oferece uma medida do progresso dos alunos que independe do desempenho absoluto, podem-se tirar conclusões sobre os esforços da escola sem ter que recorrer a estimativas e pesos subjetivos. Portanto, em termos teóricos, a medida do valor agregado da escola permite não só controlar pelas origens e pelo desempenho prévio dos alunos, mas também exclui a necessidade de arbitrar pesos ou compensações para tornar o sistema de bonificação mais equitativo.

A comparação dos resultados da escola, ao longo de um período de dois ou mais anos, pode ser entendida como uma tentativa de criar uma medida semelhante ao de valor agregado. Essa metodologia foi empregada pela política Nova 
Escola no Rio de Janeiro e também consta das políticas de premiação do Estado do Ceará. Ao estabelecer um prêmio para as escolas que mais conseguem melhorar seus resultados de um ano para outro sem estipular níveis mínimos de desempenho, os responsáveis criam um critério de bonificação que possa beneficiar escolas com clientelas pobres, contanto que mostrem avanços superiores às outras.

Embora esse modelo de premiação possa reduzir o impacto do nível anterior de aprendizagem e controlar, portanto, pela origem social dos alunos, ele não oferece controles pelos diferentes ritmos de aprendizagem de diferentes grupos sociais, ou pelas mudanças de um ano para outro nos outros fatores associados ao nível de desempenho dos alunos de determinada série escolar. Entre esses fatores, encontra-se a variação natural nas características e na capacidade de aprendizagem dos alunos. Apesar de não se esperarem grandes diferenças no nível socioeconômico da clientela da escola de um ano para outro, pode haver diferenças suficientes entre as turmas de diferentes anos para alterar a média de desempenho para cima ou para baixo, a ponto de alterar o status da escola perante a política de bonificação (HANUSHEK; RAYMOND, 2003).

A única forma de evitar a variação aleatória nas características dos alunos é operacionalizar um processo de avaliação longitudinal, que permite acompanhar a evolução na aprendizagem dos mesmos alunos ao longo de um período de tempo. Nesse desenho, a variação no desempenho dos alunos no período pode ser atribuída, de fato, ao trabalho dos professores e ser usada como critério livre de viés socioeconômico para determinar o esforço da escola. Não resolve o problema do ritmo de progresso na aprendizagem depender do ponto de partida do aluno no começo do período em estudo, o que dificulta a bonificação das escolas cujos alunos estão mais adiantados, mas permite uma distribuição da premiação que possa beneficiar tanto escolas da periferia quanto dos bairros mais centrais.

Não se deve subestimar as dificuldades práticas associadas ao acompanhamento longitudinal de todos os alunos do sistema. A intensa movimentação dos alunos entre escolas 
e sistemas, a descontinuidade no fluxo dos alunos provocada pela retenção e a falta de cuidado no registro dos nomes são só algumas das dificuldades associadas ao controle correto do cadastro, indispensável para a análise longitudinal dos ganhos na aprendizagem. Mesmo assim, a metodologia oferece vantagens claras para uma política de equidade. Permite identificar as escolas que mais precisam de socorro ao mesmo tempo em que estabelece as bases para uma remuneração variável calcada em critérios justos.

\section{EFEITOS COLATERAIS DOS TESTES HIGH STAKES}

Outras considerações, mais relacionadas com os resultados dos alunos e menos com a questão de equidade, foram sumarizadas no momento da criação do Movimento Contra Testes de Alto Impacto em Educação, no âmbito da 33a Reunião da Associação Nacional de Pós-Graduação e Pesquisa em Educação (ANPEd) em 2010. Derivado de uma leitura sobre a experiência de outros países, o documento do Movimento trata dos efeitos colaterais dos testes de alto impacto (high stakes), como no caso das avaliações dos estados brasileiros que criaram políticas de incentivos monetários vinculados aos resultados dos alunos. Esses efeitos incluem a capacidade de falsear os dados das avaliações, induzir à desonestidade, substituir os esforços de ensino pela mera preparação dos alunos para os testes e, em consequência, estreitar o currículo, além de provocar ansiedade em alunos, pais, professores e administradores (MOVIMENTO, 2010).

As preocupações do Movimento também estão no documento de debate recente do Conselho Nacional de Educação intitulado "Diretrizes Conceituais e Operacionais para a Avaliação na Educação Básica (Subsídios)” (BRASIL, 2012). Entre suas considerações finais, o documento subscreve uma série de possíveis normas para o funcionamento de um sistema nacional de avaliação sugeridas por Luiz Carlos Freitas, Professor da Unicamp. Entre elas, está incluída a necessidade de evitar avaliações de alto impacto (high stakes) "associadas a consequências fortes, pelo potencial que estas últimas 
apresentam de corromper os próprios indicadores da educação básica e gerar fraudes”, a não utilização de resultados de testes de desempenho de alunos "como base para incentivo e para cálculo de pagamento de salário dos profissionais da educação" (BRASIL, 2012, p. 24) pela falta de evidência empírica que permita avaliar as possíveis consequências da política em solo brasileiro. Nesse caso, o autor é da opinião que estender uma política dessa natureza a uma rede de ensino inteira sem ter de antemão um corpo de evidências sobre seus possíveis impactos demonstra uma falta de ética.

Deve-se supor que as evidências desejadas sejam de pesquisas nacionais sobre o tema. Apesar da rejeição da política de avaliação high stakes com base em pesquisas e depoimentos sobre seu funcionamento em outros países, principalmente nos Estados Unidos, no caso especifico dos incentivos monetários exigem-se pesquisas e evidências locais como requisitos para a formulação de políticas similares. Perante tanta informação de outros sistemas, inclusive de países em desenvolvimento, essa exigência parece ser um tanto rigorosa. Há múltiplos casos de políticas autóctones pioneiras que foram testadas com base na sua implantação em rede inteira, como no caso da Escola Plural de Belo Horizonte, como há casos de políticas adotadas via processos de policy borrowing após o estudo da sua introdução anterior em outras conjunturas, como no caso da avaliação em larga escala. A história da reforma educacional brasileira está repleta de exemplos de adaptação e internalização de ideias formuladas originalmente em outros contextos e que, posteriormente, foram expressas na forma de políticas sistêmicas, sem passar por projetos pilotos ou outras modalidades de experimentação (BROOKE, 2012).

De fato, a literatura internacional sobre as avaliações high stakes está repleta de avisos sobre as possíveis consequências negativas de se formar uma associação entre os resultados dos alunos e algum tipo de consequência de valor para os professores. O fenômeno do aumento gradativo nos resultados dos alunos, chamado de "inflação", sem significar necessariamente alguma melhora no nível de aprendizagem, é indicativo de práticas provavelmente indesejáveis, 
tanto em termos educacionais quanto éticos. E dependendo da situação, a avaliação high stakes pode introduzir um viés nos resultados que diminua sua serventia tanto como instrumento pedagógico quanto de gestão.

Mas essa literatura também contém numerosos estudos que mostram efeitos positivos de avaliações high stakes em termos de ganhos na aprendizagem dos alunos. Incluem-se, neste grupo, as pesquisas que tratam especificamente da avaliação de diferentes metodologias para o cálculo e o pagamento de incentivos monetários para diferentes níveis e tipos de ensino. O que, efetivamente, impede a apreciação da política de incentivos não é bem a falta de evidências empíricas, senão o excesso delas e a dificuldade de separar o joio do trigo.

\section{PESQUISA SOBRE SISTEMAS DE INCENTIVO MONETÁRIO}

Quando a pesquisa se concentra na comparação dos resultados dos alunos de acordo com a presença ou não de sistemas de pagamento de incentivos, os resultados nos Estados Unidos são contraditórios. Usando dados de um experimento natural em um distrito escolar onde uma escola de ensino médio adotou um sistema de incentivos e outra não, Eberts e colegas (2000) não conseguiram mostrar impacto na média dos alunos, mas constataram que a proporção de alunos evadidos diminuiu significativamente (EBERTS; HOLLENBECK; STONE, 2000). Figlio e Kenny (2006), por outro lado, com base na Pesquisa Longitudinal Nacional sobre Educação (NELS National Education Longitudinal Study), encontraram resultados melhores em escolas com sistemas de incentivos, mas pela natureza dos dados não puderam descartar a possibilidade desses resultados terem sido causados pela adoção dos sistemas de incentivos pelas melhores escolas (FIGLIO; KENNY, 2006). Resultados mais convincentes foram encontrados por Winters et al. (2008) em estudo do sistema de incentivos de Little Rock, Arkansas, onde os alunos dos professores incluídos no programa obtiveram ganhos substanciais (WINTERS et al., 2008), e por Atkinson et al. (2009), na Inglaterra, onde o 
ganho equivalia a aproximadamente $40 \%$ de um ano escolar por aluno (ATKINSON et al., 2009).

Outros autores são menos otimistas e enfatizam possíveis efeitos negativos dos sistemas de incentivos, incluindo a erosão da motivação intrínseca inerente à docência pela motivação extrínseca mais instrumental. Springer (2009) menciona a perda do ambiente colaborativo e a instalação de interesses mais competitivos, ao mesmo tempo em que critica a incapacidade dos testes de retratar a complexidade multitarefa do trabalho do professor. Um relatório da Corporação Rand também trata da possibilidade de efeitos negativos no ânimo dos professores, no espírito de colaboração entre membros da equipe e no desempenho dos alunos (RAND, 2009). Os trabalhos que não detectam ganhos entre os alunos de professores incluídos em programas de incentivos mostram a importância de pequenas variações no próprio desenho dos programas e a necessidade de envolver os interessados no processo de formulação (PRINCE et al., 2008).

Quando a pesquisa faz a distinção entre sistemas de incentivos individuais e sistemas de incentivos coletivos, pagos a todos os integrantes da equipe escolar, independentemente de terem sido ou não os professores dos alunos testados, os resultados se tornam mais relevantes para a situação brasileira. Com a exceção do prêmio para os professores alfabetizadores de Sobral (CE), os incentivos brasileiros são coletivos, pagos, mediante fórmulas diversas, à coletividade escolar com justificativas que geralmente explicitam o propósito de motivar a equipe inteira e evitar possíveis divisões causadas pelos incentivos individuais. Os motivos pela escolha do incentivo coletivo também são práticos. Como explicado por Ahn e Vigdor (2010), a concentração da avaliação em poucas áreas curriculares e em só algumas séries escolares reduz o número de professores cujos alunos são efetivamente testados, mesmo nos Estados Unidos (AHN; VIGDOR, 2010). O segundo problema é a distribuição não aleatória de alunos entre as turmas e a consequente distribuição enviesada de resultados e incentivos entre os professores. $\mathrm{O}$ terceiro problema é que os instrumentos de avaliação e os 
métodos estatísticos para determinar a relação entre os resultados dos alunos e o trabalho do professor ainda sofrem de flutuações aleatórias e outras imprecisões que dificultam seu emprego para incentivos individuais.

Apesar das aparentes vantagens do incentivo coletivo, a pesquisa não demonstra o mesmo impacto. Goodman e Turner (2010), por exemplo, mostram pouco efeito para incentivos de grupo pagos de acordo com o grau de cumprimento de metas pela escola. Em pesquisa conduzida no sistema público de Nova York, foram criadas diversas medidas de resultados, incluindo esforço docente, desempenho dos alunos em matemática, leitura e práticas de sala de aula. Foi detectada a prática de free-riding, em que os professores cujos alunos não foram testados não procuraram se esforçar, o que reduziu significativamente o efeito dos incentivos do programa. Em escolas com um número menor de professores, os incentivos levaram a uma melhora significativa na frequência dos professores, mas essa mudança não se traduziu em ganhos nos resultados dos alunos (GOODMAN; TURNER, 2010).

Perante esse cipoal de resultados contraditórios, o que faz falta para nós observadores é uma metapesquisa de fonte confiável que, aplicando critérios rigorosos para a seleção de pesquisas, permita que se chegue a uma conclusão sobre os efeitos dos incentivos monetários. Publicação recente do Comitê sobre Incentivos e Accountability Baseado em Testes na Educação Pública, do National Research Council, dos Estados Unidos, parece cumprir esse papel em relação às pesquisas dos últimos 10 anos não só nos Estados Unidos, mas também em outros países (HOUT; ELLIOTT, 2011).

A metapesquisa do National Research Council estabelece uma série de critérios para a exclusão de estudos que, por motivos metodológicos, não atingem um grau satisfatório de confiabilidade. O primeiro critério é que os estudos precisam de grupo de controle, para poder provar que os incentivos são efetivamente a causa das mudanças na aprendizagem. $\mathrm{O}$ segundo critério obriga o uso de um teste independente low stakes para medir o efeito dos incentivos sobre a aprendizagem. Pelo conhecido efeito de "inflação" de resultados nos testes usados para determinar o pagamento de bonificações, 
os autores insistem que esses mesmos testes não podem servir como medida para aferir o impacto da política. O terceiro critério exclui os estudos transversais que comparam os resultados de escolas incluídas e não incluídas em programas de incentivos que não controlaram por meio dos critérios usados pelas autoridades educacionais na decisão de inclusão/exclusão. Sem esse controle, as diferenças encontradas no desempenho dos alunos podem ser atribuídas a quaisquer outras diferenças no funcionamento das escolas e não necessariamente no uso de incentivos.

São 11 os estudos que satisfazem os critérios e oferecem uma base para conclusões confiáveis, cinco dos Estados Unidos e seis de outros países. Nos Estados Unidos as pesquisas mostram que os programas de incentivos não têm influenciado os níveis de desempenho dos alunos de forma consistente e significativa. O efeito médio varia de $-0,02$ a 0,06 desvios padrão nas escalas usadas quando os programas são avaliados pelo uso de testes low stakes de controle.

Entre os estudos usados como base para essa conclusão encontra-se o de Springer et al. (2010), que conduziram um experimento na cidade de Nashville ao longo de três anos, o qual entregava um bônus de $\mathrm{R} \$ 5.000,00$ a $\mathrm{R} \$ 15.000,00$ para professores de matemática cujos alunos alcançavam o critério de $85 \%$ na distribuição distrital. Usando medidas de valor agregado, os pesquisadores encontraram efeitos positivos do bônus na $5^{\mathrm{a}}$ e $6^{\mathrm{a}}$ séries e negativos na $7^{\mathrm{a}}$ e $8^{\mathrm{a}}$ séries (SPRINGER et al., 2010). Em pesquisa de dois anos conduzida em Chicago para avaliar os ganhos dos alunos de professores com bônus de até $\mathrm{R} \$ 12.000,00$, Glazerman e Seifullah (2010) encontraram resultados menos contraditórios. Das 10 combinações de matéria/ano usadas como variáveis dependentes, oito mostraram resultados negativos, mas sem significância estatística. O único efeito positivo foi o da taxa de retenção dos professores.

$\mathrm{Na}$ avaliação do sistema de incentivos implantado no Texas em 1996, Jackson (2010) estudou o desempenho de alunos do ensino médio cujos professores podiam ganhar de $\mathrm{R} \$ 500,00$ a $\mathrm{R} \$ 1.000,00$ para cada aluno com pontuação de três ou mais em testes de advanced placement, um instrumento 
usado na seleção de candidatos ao ensino superior (JACKSON, 2010). O pesquisador encontrou um aumento de 1 a $2 \%$ ao ano na proporção de alunos atingindo o critério e um aumento de 5,3\% em alunos indo para faculdade. Nas 1200 escolas incluídas no Programa Para o Avanço de Professores em dois estados, Springer e colegas (2008) estudaram os ganhos em matemática de um painel de alunos entre a $2^{\mathrm{a}}$ e a $5^{\mathrm{a}}$ séries. Encontraram ganhos significativos de até 0,2 d.p. (desvio padrão) ${ }^{6}$ de acordo com o tipo de bônus. Para os alunos da $7^{\mathrm{a}}$ à $10^{\mathrm{a}}$ série, não houve ganho nem decréscimo nos resultados. Do total de 18 combinações de matéria/ano na pesquisa toda, houve um ganho médio de somente 0,01 d.p. (SPRINGER; BALLOU; PENG, 2008).

Especialmente interessante para nós, os estudos de outros países que satisfizeram os critérios da metapesquisa incluem pesquisas realizadas na Índia e Israel. O impacto dos incentivos nesses países são maiores, com um efeito médio de 0,08 d.p. No caso indiano, Muralidharan e Sundararaman (2009) realizaram um experimento de dois anos sobre o impacto de um bônus de $3 \%$ do salário na aprendizagem de matemática e língua, concedido de forma individual ou coletiva. O ganho médio foi de 0,19 d.p., mas com extremos de 0,22 d.p., no caso de matemática, nas escolas com incentivos individuais, e 0,15 d.p. nas escolas com incentivos coletivos.

Os autores da metapesquisa relutam em chegar a conclusões gerais pelo fato de existirem muitos desenhos de políticas de incentivos ainda sem experimentação e muita variação entre os desenhos já testados. Mesmo assim, eles acreditam que os benefícios são bem menores do que o esperado e pouco convincentes perante o tamanho do desafio para melhorar os resultados das escolas. Observam também que os custos são altos, o que não deveria ser tomado como razão para deixar de investir em outras políticas de melhoria, potencialmente mais eficazes.

É digna de atenção, no entanto, a diferença substancial entre os resultados nos Estados Unidos e os dos outros países. Esta diferença permite-nos especular sobre a variação entre os países no que se refere ao ambiente de responsabilização e o valor e significado dos programas de incentivo monetário
6 Pela falta de comparabilidade das escalas usadas pelos diferentes sistemas de avaliação, os autores desse e de outros estudos costumam empregar o desvio padrão para expressar a diferença entre as médias dos grupos e, portanto, como medida da variação provocada pelo pagamento de incentivos. Quanto maior a diferença em desvio padrão, maior o impacto. Nas escalas Saeb, 0,2 desvio padrão corresponde ao intervalo entre 9 e 12 pontos, dependendo da matéria e ano. Acesso em: dez. 2012. 
para os professores envolvidos. No caso dos Estados Unidos, esse ambiente é intenso, sobretudo após a aprovação em 2001 da legislação federal chamada de Nenhuma Criança Será Deixada para Trás, ou No Child Left Behind (NCLB). O NCLB aumentou significativamente as obrigações dos estados na aplicação de avaliações, estipulou metas de accountability para escolas, distritos e estados e legislou sobre o "progresso anual aceitável" para todos os alunos e subgrupos de alunos por nível socioeconômico, raça, língua materna e necessidade especial (LINN; BAKER; BETEBENNER, 2002). As avaliações anuais foram ampliadas para abranger todos os alunos entre a $3^{\mathrm{a}}$ e a $8^{\mathrm{a}}$ série, juntamente com recomendações para a formulação de padrões curriculares; e as metas anuais, para que todos os alunos alcancem "proficiência" até o ano de 2014, são acompanhadas de uma série de provisões caso a escola não cumpra sua tarefa. Essas variam desde o direito dos pais de levarem seus filhos para outras escolas até o fechamento e "reconstituição" da escola que não alcança o progresso anual adequado por vários anos consecutivos (HAERTEL; HERMAN, 2005). A este ambiente de responsabilização legal e moral, deve-se acrescentar a pressão exercida pelos pais e pelos próprios alunos, que dependem dos seus resultados para progredirem dentro do sistema.

Nesse contexto, de níveis altos e preexistentes de preocupação com os resultados dos alunos, deve-se supor que o impacto adicional de incentivos monetários seja pequeno, certamente menor que em países onde a política de responsabilização só agora começa a se definir, justamente por meio de políticas de incentivos. Nesses outros países, pode-se esperar um impacto maior, tanto pela singularidade da política quanto pelo efeito da novidade. $\mathrm{O}$ fato dos resultados dos incentivos serem mais evidentes em países onde os salários dos docentes são consideravelmente menores que nos Estados Unidos levanta outra hipótese sobre a relação entre incentivos e os níveis absolutos dos salários dos professores. Seria razoável supor que, onde os salários são pequenos e os professores se sentem mal remunerados, o bônus seja visto com olhos bem mais positivos, independentemente do seu valor como proporção do salário total. 


\section{PESQUISA BRASILEIRA}

São sete os estados brasileiros com alguma experiência em política de incentivos monetários - Amazonas, Ceará, Pernambuco, Rio de Janeiro, Minas Gerais, Espírito Santo e São Paulo. Há também notícias de municípios que encampam versões dessa mesma política, usando seus sistemas próprios de avaliação como no caso da cidade de São Paulo, ou fazendo uso dos indicadores fornecidos pelo Instituto Nacional de Estudos e Pesquisas Educacionais Anísio Teixeira (Inep) para definir os critérios de distribuição. Exemplos dessa segunda tendência municipal seriam Trairão, pequena cidade no sudoeste do Pará, onde a secretaria de educação dá $\mathrm{R} \$ 1.000,00$ aos professores e R \$ 500,00 às escolas que apresentam “desempenho melhor", e Careiro (AM), onde os professores recebem $14^{\circ}$ e $15^{\circ}$ salários se a escola tirar nota 5,1 ou melhor no Índice de Desenvolvimento da Educação Básica (Ideb).7

Mesmo com a expansão na experimentação com diferentes modalidades de bonificação, a pesquisa nacional sobre a política de incentivos monetários ainda é incipiente. Existem relatos esparsos, geralmente por parte de porta-vozes dos governos responsáveis, como no caso da gerente de Informação e Avaliação Educacional da Secretaria de Educação do Espírito Santo, que vê relação estreita entre o Bônus Desempenho e o crescimento no IDE das escolas de 43,01\% em 2009 para 49,68\% em 2011. O tom geralmente positivo dessas manifestações é previsível e não substitui a avaliação controlada dos impactos.

A primeira tentativa de avaliar as consequências de incentivos monetários foi o estudo de Rodrigues (2007) sobre a política Nova Escola do Estado do Rio de Janeiro que comparou os resultados das escolas de ensino médio daquele estado com os de dois outros estados no sudeste brasileiro de 2000 a 2005 (RODRIGUES, 2007). Os resultados em questão foram a média das notas do Sistema Nacional de Avaliação da Educação Básica (Saeb) para os três estados (coletadas a cada dois anos entre 1995 e 2005) e as médias da relação aprovação/reprovação e da taxa de evasão do censo escolar. A despeito da falta de controles para outras possíveis diferenças de políticas educacionais ou para mudanças na situação econômica relativa dos
7 Segundo notícias veiculadas pela Educação na Mídia, do Todos pela

Educação, em 02/09/2011. Disponível em: <http://www.todospelaeducacao.org.br/>. Acesso em: dez. 2012 
três estados, o estudo mostra ganhos maiores no desempenho em Português no Rio de Janeiro em relação aos outros estados, invertendo uma posição de inferioridade vigente durante o período anterior à criação do Programa Nova Escola. Apesar de apresentar pioras ao invés de melhorias, as estatísticas de fluxo também mostram que a reprovação média dos alunos no final do ano cresce mais devagar no Rio de Janeiro do que nos outros estados. No entanto, outros resultados tornam essas descobertas menos conclusivas. Os resultados do desempenho em matemática mostram tendência inversa à de português, $\mathrm{e}$ o Rio de Janeiro perde terreno comparativamente aos outros estados. Como a matemática é uma matéria mais "escolar" do que o português (BRANDSMA; KNUVER, 1989), o resultado esperado era o oposto. O nível de evasão também aumentou em comparação com os outros estados, levantando a possibilidade de que as taxas de reprovação, menores do que o esperado, possam ser fruto de uma autosseleção por parte dos alunos. A despeito do grande esforço em sujeitar o Programa Nova Escola a uma avaliação objetiva, a ambiguidade dos resultados indica que outros estudos serão necessários.

Recém-apresentado em versão preliminar, um estudo sobre os incentivos criados pela Secretaria de Educação de Pernambuco vai permitir uma avaliação mais rigorosa da política de bonificação (FERRAZ; BRUNS, 2012). A versão da política em questão foi lançada em 2008 junto com a pactuação de metas para a melhoria dos resultados das escolas estaduais baseadas no Indicador de Desenvolvimento Educacional de Pernambuco (Idepe), criado com base em uma metodologia análoga à do Ideb. Para as escolas de desempenho no quartil inferior da distribuição do Idepe, foi usada como meta a nota do Ideb de 2009. Para as escolas de desempenho intermediário, a meta foi definida para superar em $10 \%$ o estado do Nordeste com melhor desempenho. Por último, para o grupo de escolas com desempenho superior, as metas foram estipuladas pelo valor do estado com melhor desempenho no Brasil. A natureza ambiciosa das metas refletiu a urgência do governo em tirar Pernambuco do último lugar no Ideb (de 2007) entre os sistemas estaduais de Ensino Fundamental. 
O Estado aloca um valor fixo por ano equivalente a um mês da folha de pagamento que é distribuído entre as escolas que alcançam 50\% ou mais das suas metas. Portanto, o tamanho do bônus depende também do nível de desempenho das outras escolas. Para determinar a proporção da meta atingida pela escola, é feito um cálculo em duas etapas, segundo Ferraz (2009). Calcula-se primeiro um índice que represente o quanto a escola deveria melhorar para cumprir a meta - o Índice de Cumprimento (IC) - e depois o Índice de Progresso (IP), para estimar o quanto a escola efetivamente progrediu. A média para cada série é ponderada pela proporção de alunos em cada ciclo. Finalmente, a proporção da meta global atingida pela escola é calculada pela divisão do que a escola efetivamente atingiu, o IP, pelo índice de cumprimento das metas, o IC. A remuneração por desempenho, paga somente para as escolas cujo índice de cumprimento global seja pelo menos de 50\%, torna a política mais severa que em outros estados. Esse desenho levou à distribuição do bônus a 52\% das escolas em 2009, com um pagamento médio de 1,8 salários e a $79 \%$ em 2010, com um pagamento médio de 1,4 salários.

Ao comparar os resultados das escolas estaduais de Pernambuco com escolas estaduais de outros estados do nordeste e com escolas municipais do mesmo estado, os pesquisadores puderam mostrar de forma convincente o impacto causado pela política de metas e incentivos. No caso da matemática do $9^{\circ}$ ano, por exemplo, no período entre 2007 e 2009, as escolas estaduais de Pernambuco eliminaram a diferença de resultados na Prova Brasil que as deixavam em desvantagem em relação aos outros estados do nordeste. No mesmo período as escolas estaduais também eliminaram a diferença em relação às escolas municipais (BRUNS; FERRAZ, 2011).

Para saber se as mudanças observadas tinham significância, os autores usaram a técnica estatística chamada diferenças em diferenças, com base nas mesmas comparações e chegaram a três conclusões importantes. A primeira é que as escolas com metas mais ambiciosas alcançam avanços maiores. Em quase todas as categorias de ano/disciplina, as escolas que ficaram do lado mais exigente dos limites de desempenho mostraram ganhos maiores que as escolas que 
ficaram abaixo dos limites. Ou seja, no curto prazo, metas mais exigentes e um incentivo atraente resultaram em melhorias nos níveis de aprendizagem.

A segunda conclusão é que as escolas que por pouco não receberam o bônus em 2009 melhoraram mais no ano seguinte que as escolas que por pouco conseguiram o bônus naquele ano. Parece lógico concluir, portanto, que não receber o bônus teve um efeito positivo na motivação e desempenho posterior da escola.

A terceira conclusão se deriva do interesse dos pesquisadores em entender o efeito do bônus em termos pedagógicos, o que os levou a observar e analisar a prática de uma amostra de professores. Nessa parte da pesquisa, constataram-se grandes disparidades no uso efetivo do tempo de sala de aula. Essas diferenças, e as diferenças no tempo em que os professores tratavam de assuntos não relacionados à aula ou que se ausentavam da sala, estavam altamente correlacionadas com a probabilidade de a escola ganhar o bônus referente ao ano escolar 2009. A identificação dos correlatos dos ganhos na aprendizagem dos alunos em termos dos comportamentos dos professores abre uma série de indagações sobre a capacidade dos incentivos de mudar aspectos da rotina do professor e contribuir para a melhoria na qualidade do ensino.

Fora do escopo da pesquisa de Pernambuco, mas de grande relevância para a discussão sobre a política de incentivos, seria uma investigação mais qualitativa sobre possíveis mudanças no relacionamento entre os membros da equipe escolar, sobre a forma de planejar as aulas e priorizar os conteúdos e sobre as atitudes assumidas na época da aplicação dos testes do sistema estadual de avaliação. Esses são aspectos do ambiente escolar que poderiam ser alterados em função dos testes high stakes. Devido às criticas dirigidas aos testes pela sua capacidade de provocar um estreitamento do currículo e de reduzir o ensino a um processo de preparação para as provas, torna-se vital que esses estudos sejam realizados em escolas onde as políticas de incentivos têm criado consequências high stakes para os sistemas de avaliação.

Chama a atenção a ausência de tais estudos, ou de qualquer outro registro de problemas pedagógicos provocados 
pelos testes nos lugares onde já há uma experiência acumulada com a política de incentivos, como no caso do Ceará. Se os impactos dessa política fossem de fato tão devastadores, era de se esperar pelo menos algum registro do fenômeno. $\mathrm{O}$ único estudo que se tem notícia diz respeito à pressão sentida por professores de matemática das séries testadas pelo Sistema Mineiro de Avaliação da Educação Pública (Simave), em Minas Gerais. Nesse caso, a pressão é exercida pelos colegas professores que procuram melhorar os resultados da escola e a proporção do bônus pago sob o regime do Acordo de Resultados implantado em 2008 (SOARES, 2011). O autor não discute se a pressão é benéfica ou prejudicial aos resultados do trabalho dos professores.

\section{CONCLUSÕES}

Após décadas de investimento na construção e em equipamento das escolas, e no fornecimento dos materiais essenciais a um ensino de qualidade, tornou-se evidente que sem políticas de equidade, que fazem uma discriminação positiva a favor das escolas localizadas em regiões que concentram famílias de baixa renda, as diferenças nos resultados de alunos de origens sociais diferentes não serão mudadas. Nessas escolas, a baixa aprendizagem, o abandono e a consequente perda de talentos precisam ser combatidos por meio de políticas de equidade que ofereçam condições especiais para os alunos e seus professores. Para funcionarem, essas políticas necessitam de duas coisas: primeiro, um acompanhamento constante dos resultados e, segundo, critérios para o remanejamento de novos recursos em direção àquelas escolas que estão em desvantagem.

De todos os recursos da escola, o mais importante é o professor, mas nem todos os professores são iguais em termos de dedicação e talento. Como promover a melhoria do quadro de professores das escolas que mais precisam de professores de maior capacidade? A resposta tradicional seria o investimento em formação continuada e a melhoria nas condições de trabalho nas escolas priorizadas de modo a 
qualificar o quadro preexistente de professores. Outra solução, levantada por Maria Alice Setubal (2012), seria por meio de incentivos monetários a serem oferecidos aos professores de maior talento para que se disponham a trocar suas escolas atuais pelas escolas priorizadas.

Os problemas da segunda opção são vários e incluem a dificuldade de determinar a quem se deve oferecer o incentivo monetário e a dificuldade de remanejar para fora da escola priorizada os professores que não satisfazem os critérios para receberem o incentivo. Ambas as decisões dependem de uma avaliação prévia das competências dos professores que até agora nenhuma rede se prontificou a organizar. A avaliação docente via provas de conhecimentos de conteúdos não seria suficiente pela sua incapacidade de verificar a competência pedagógica do professor e o seu desempenho em sala de aula com alunos pertencentes ao grupo priorizado.

Nessa situação, o mais razoável seria associar o incentivo aos resultados da escola da forma prevista por aquelas políticas de bonificação que incorporam uma correção de acordo com o esforço da escola, calculado com base nas origens dos alunos e do nível de ensino oferecido. Dependendo dos resultados da escola, essas correções podem ser calibradas de modo a permitir que escolas que apresentem grandes desafios em termos de características socioeconômicas das clientelas também apareçam entre as instituições premiadas. Junto com as bonificações, deve-se pensar em políticas adicionais, voltadas para o aperfeiçoamento do corpo docente, que aproveitem o grau de interesse e mobilização dos professores propiciada pelos incentivos.

A tese desenvolvida, que em princípio não há incompatibilidade entre políticas de equidade e políticas de bonificação, tem duas lacunas. A primeira diz respeito às escolas que mesmo com as correções pelo nível socioeconômico dos alunos não alcançam o nível de desempenho fixado como mínimo. O risco nesse caso é a escola deixar de se esforçar após a confirmação da sua classificação entre as não bonificadas. No caso do Chile, por exemplo, sabe-se que o incentivo tem um efeito cumulativo e positivo no desempenho dos alunos para aquelas escolas que possuem boas chances de ganhar 
o prêmio, mas que não há efeito para a quase metade das escolas que nunca foram premiadas (MIZALA; ROMAGUERA, 2005). Mesmo com uma política cuja formulação permita o pagamento de uma proporção do bônus de acordo com a proporção das metas de desempenho cumpridas, ainda há o risco da escola priorizada pela política de equidade receber menos bonificação que outras.

A outra lacuna é a incerteza em relação ao real impacto dos incentivos no Brasil. As pesquisas realizadas nos Estados Unidos que satisfazem os rigores da metapesquisa da National Research Council não inspiram muita confiança no que diz respeito às vantagens da política. Quando os resultados dos programas de incentivos são traduzidos em desvios padrão na escala que mede os ganhos na aprendizagem dos alunos, os efeitos são positivos, mas muito próximos a zero. Apesar de seus custos e do grau de convicção de seus defensores, as políticas de incentivos monetários nos Estados Unidos se mostram quase inócuas.

No entanto, como foi observado, o contexto em que a política de incentivos é adotada naquele país é muito diferente do brasileiro, o que reduz a relevância e aplicabilidade dos resultados das pesquisas resenhadas. Quando a mesma política é implementada em outros contextos, talvez mais parecidos com o Brasil, os ganhos são mais evidentes, como nos casos de Israel e Índia. Nesses dois países, mesmo os bônus coletivos têm efeitos positivos e suficientes para justificar o investimento. A diferença nos impactos dos incentivos em contextos diversos sinaliza a relevância do meio educacional e cultural e confirma a importância de prosseguir com a pesquisa nacional.

As primeiras evidências de uma pesquisa em Pernambuco sobre as consequências dos incentivos indicam efeitos positivos, não só no nível geral de desempenho dos alunos da rede estadual em relação a outras redes e estados, mas também no nível de motivação das escolas com metas mais ambiciosas e daquelas que, apesar de próximas à linha de corte, não receberam o bônus na primeira distribuição.

Em relação a este último achado, precisa-se fazer uma série de novas perguntas que talvez só sejam respondidas 
após mais alguns anos de experimentação. A primeira delas é se o bônus continuará exercendo seu efeito positivo sobre as escolas que não foram contempladas nas distribuições anteriores. Para que haja continuidade, a escola precisa ter confiança na metodologia do bônus e acreditar que a distribuição seja mesmo fruto do esforço e competência dos seus professores. Se os professores não discernirem legitimidade na distribuição, por falta de coincidência clara entre o mérito aparente das escolas e o recebimento do bônus, os efeitos da política serão de curta duração, tanto entre as escolas que já receberem o bônus quanto entre as que não receberam.

Em outras palavras, a qualidade técnica da política é crucial para entender seus efeitos. A metodologia precisa ser robusta, baseada em várias medidas de aprendizagem para superar a influência dos erros inerentes a qualquer prova, e levar em consideração os fatores fora do alcance da escola que possam influenciar seus resultados. Nesse sentido, as metodologias de $2^{\text {a }}$ geração empregadas pelos estados do Espírito Santo e Pernambuco representam um avanço importante sobre os métodos de $1^{\text {a }}$ geração do Ceará, onde ainda não existem controles para o efeito da condição socioeconômica dos alunos. As metodologias novas também incorporam um elemento de equidade no cálculo do indicador de desenvolvimento da escola ao dividir os alunos por diferentes faixas de desempenho e cobrar a melhoria em todas elas. Dessa forma, a escola fica incentivada a melhorar os resultados em todas as turmas em vez de se fixar nos melhores alunos visando somente à melhoria da média geral.

Certas dificuldades técnicas ainda, no entanto, permanecem. As medidas de controle baseadas no nível socioeconômico dos alunos, em alguns casos, ainda se baseiam em valores arbitrados e não no impacto real do nível socioeconômico ou outros características dos alunos. Também não resolvem o problema da falta de medida do desempenho anterior dos alunos, que impede que seja calculada a contribuição específica da escola à aprendizagem dos alunos. Não há duvida de que a melhor medida para o desempenho dos alunos seria a medida longitudinal em que os mesmos são monitorados ao longo de um período de tempo com base em uma 
primeira avaliação servindo de linha de base. O resultado destas medidas longitudinais, em termos de ganhos médios de aprendizagem da coorte de alunos, pode ser considerado um cálculo mais exato do valor agregado da escola porque além de controlar pelo efeito da aprendizagem prévia, controlam-se também as flutuações na composição das turmas.

Mesmo com todos os cuidados técnicos, haverá sempre o risco das provas usadas como critério para o cálculo das bonificações provocarem inflação nos resultados dos alunos, além de todos os outros efeitos colaterais associados às avaliações high stakes. A ausência de registros ou de resultados de pesquisa nacional para identificar exemplos concretos desses efeitos negativos não permite dizer que não haja um risco associado às políticas de incentivos monetários. Precisa haver um esforço para mostrar como as escolas se organizam em um regime de incentivos e como os professores responsáveis pelas turmas testadas se comportam perante seus colegas; se há evidência de distorções no currículo e empenho em falsear os resultados. Até existirem essas evidências sempre haverá dúvidas se os efeitos colaterais são mais graves em outros contextos culturais e de consequências menos danosas na escola brasileira.

\section{REFERÊNCIAS}

AHN, T.; VIGDOR, J. The impact of incentives on effort: teacher bonuses in North Carolina. Harvard, 2010. (PEPG 10-06).

ATKINSON, Adele et al. Evaluating the impact of performance-related pay for teachers in England. Labour Economics, v. 16, n. 3, p. 251-261, jun. 2009.

BRANDSMA, H.; KNUVER, J. Effects of school classroom characteristics on pupil progress in language and arithmetic. International Journal of Educational Research, v. 13, n. 7, p. 777-788, 1989.

BRASIL. Conselho Nacional de Educação. Diretrizes conceituais e operacionais para a avaliação na educação básica: Subsídios. Brasília: Documento pdf. Maio, 2012. 27 p.

BROOKE, N. As perspectivas para as políticas de responsabilização educacional no Brasil. Cadernos de Pesquisa, São Paulo, v. 36, n. 128, p. 377-401, 2006. ISSN 0100-1574. Disponível em: <http://www.scielo.br/scielo.php?script=sci_ issuetoc\&pid=0100-157420060002\&lng=en\&nrm=iso > . Acesso em: jan. 2013. 
Responsabilização educacional no Brasil. Revista Iberoamericana de Evaluación Educativa, v. 1, n. 1, p. 93-109, 2008. Disponível em: <http://www. rinace.net/riee/ numeros/vol1-num1/art7.pdf>. Acesso em: 20 out. 2010.

. As novas políticas de incentivo salarial para professores: uma avaliação. In: FONTOURA, H. A. (Org.) Políticas públicas, movimentos sociais: desafios à pós-graduação em educação em suas múltiplas dimensões. Rio de Janeiro: ANPEd Nacional, 2001. p. 163-188 (Coleção ANPED SUDESTE 2011, Livro 3). Disponível em: <http://www.fe.ufrj.br/anpedinha2011/ ebook3.pdf>. Acesso em: jan. 2013.

Marcos históricos na reforma da educação. Belo Horizonte: Fino Traço, 2012.

BROOKE, N.; CUNHA, M. A. A. A avaliação externa como instrumento da gestão educacional nos estados. In: FUNDAÇÃO VICTOR CIVITA (Ed.). Estudos e Pesquisas Educacionais - v. 2. São Paulo: Fundação Victor Civita, 2011. p. 17-79.

BRUNS, B.; FERRAZ, C. Paying teachers to perform: the effects of bonus pay in Pernambuco, Brazil. World Bank power point presentation, 7 de dezembro. Washington, DC., 2011. Disponível em: <http://siteresources. worldbank.org/EDUCATION/Resources/ppt_paying_teachers_Dec.7.2011. pdf>. Acesso em: jan. 2013.

COSTA, M. M. Bônus muda em 2013, diz secretário de Educação de SP: bonificação irá incluir critério socioeconômico, mas desempenho dos estudantes no Saresp continua sendo componente do cálculo. São Paulo: iG São Paulo, 18 abr. 2012, 18:56:23. Disponível em: <http://ultimosegundo.ig.com.br/educacao/2012-04-18/bonus-muda-em-2013-diz-secretario-de-educacao-de-sp.html.> Acesso em: jan. 2013.

D’ELBOUX, Y. Secretarias de um lado, professores de outro. Profissão Mestre. Curitiba: Disponível em: <http://www.profissaomestre.com.br/view/action/ visualizarMateria.php?cod=1107> . Acesso em: nov. 2011.

DANTAS, L. M. V. As contribuições das políticas de avaliação educacional em larga escala: o caso da avaliação de aprendizagem na Bahia. 2009. (Doutorado ) - Faculdade de Educação, Universidade Federal da Bahia, Salvador, Bahia, 2009.

EBERTS, R.; HOLLENBECK, K.; STONE, J. Teacher performance incentives and student outcomes. W.E. Upjohn Institute August, 2000.

ESPÍRITO SANTO. Secretaria da Educação. Relatório técnico modelo da bonificação. Vitória: SEE, 2010. 66 p.

FERRAZ, C. Sistemas educacionais baseados em desempenho, metas de qualidade e a remuneração de professores: os casos de Pernambuco e São Paulo. In: VELOSO, F. et al. (Ed.). Educação básica no Brasil: construindo o país do futuro. Rio de Janeiro: Elsevier, 2009. p. 239-260

FERRAZ, C.; BRUNS, B. Paying teachers to perform: the impact of bonus pay in Pernambuco, Brazil. In: CONFERENCE: Understanding Variation in Treatment Effects. Spring. 2012, Anais...Washington, DC: SREE, 2012.

FIGLIO, D. N.; KENNY, L. W. Individual teacher incentives and student performance. National Bureau of Economic Research. Cambridge, Massachusetts, 2006. 
GLAZERMAN, S.; SEIFULLAH, A. An evaluation of the Teacher Advancement Program (TAP) in Chicago: year two impact report. Mathematica Policy Research. 2010.

GOODMAN, S.; TURNER, L. Teacher incentive pay and educational outcomes: evidence from the NYC Bonus Program. Harvard University, june 2010. (PEPG 10-07).

HAERTEL, E.; HERMAN, J. L. A Historical perspective on validity arguments for accountability testing. In: HERMAN, E. H. J. L. (Ed.). Uses and misuses of data for educational accountability and improvement: 104th Yearbook of the National Society for the Study of Education. Malden, MA: Blackwell, Part II, 2005. p. 1-34.

HANUSHEK, E. A.; RAYMOND, M. E. Lessons about the design of state accountability systems. In: PETERSON, P. E.; WEST, M. R. (Ed.). No child left behind? The politics and practice of school accountability. Washington, DC: The Brookings Institution, 2003. p. 127-151.

HIDAKA, R. K. Sindicalismo docente e reforma neoliberal no Estado de São Paulo. SEMINÁRIO INTERNACIONAL DA REDE DE PESQUISADORES SOBRE ASSOCIATIVISMO E SINDICALISMO DOS TRABALHADORES EM EDUCAÇÃO (REDE ASTE), 3., 2011. Rio de Janeiro, 2011.

HOUT, M.; ELLIOTT, S. W. (Ed.) Incentives and test-based accountability in education. National Research Council Committee on Incentives and Test-Based Accountability in Public Education. Washington, DC: The National Academies Press, 2011.

JACKSON, K. C. A little now for a lot later: a look at a Texas Advanced Placement incentive program. Journal of Human Resources, v. 45, n. 3, p. 591-639, 2010.

LINN, R. L.; BAKER, E. L.; BETEBENNER, D. W. Accountability systems: implications of requirements of the no child left behind act of 2001 . Educational Researcher, v. 31, p. 3-16, 2002.

MIZALA, A.; ROMAGUERA, P. Teachers' salary structure and incentives in Chile. In: VEGAS, E. E. (Ed.). Incentives to improve teaching: lessons from Latin America. Washington, DC: The World Bank, 2005. p. 103-150 .

MOVIMENTO. Movimento contra testes de alto impacto em educação. 2010. Disponível em: <http://sites.google.com/site/movimentocontratestes/ home>. Acesso em: 4 jun. 2011.

MURALIDHARAN, K.; SUNDARARAMAN, V. Teacher performance pay: experimental evidence from India. National Bureau of Economic Research. Cambridge, Massachusetts, p.37, [11], 2009.

PRINCE, C. D. et al. Building teacher and community support for new compensation systems. Washington, DC: Center for Educator Compensation Reform, 2008.

RAND. Designing effective pay-for-performance in k-12 education: policy brief. Santa Monica, CA: Rand education, 2009.

RODRIGUES, J. R. S. Responsabilização e resultados escolares no Rio de Janeiro. 2007. Dissertação (Mestrado ) - Departamento de Educação, PUC-Rio, Rio de Janeiro, 2007. 
SETUBAL, M. A. Meritocracia nos sistemas de educação. 0 Estado de São Paulo, 18 de junho de 2010. Disponível em: <http://www.estadao.com.br/ noticias/impresso,meritocracia-nos-sistemas-de-educacao,568390,0.htm>. Acesso em: jan. 2013

. Os melhores professores para as piores escolas. Folha de São Paulo, 26 de março de 2012. Disponível em: <http://www1.folha.uol.com.br/fsp/ opiniao/33465-os-melhores-professores-para-as-piores-escolas.shtml>. Acesso em: jan. 2013

SHULHA, L. M.; COUSIN, J. B. Evaluation use: theory, research and practice since 1986. American journal of Evaluation, v. 18, p. 195-208, 1997.

SOARES, C. R. Sistemas de avaliações em larga escala na perspectiva histórico-cultural: o caso do Sistema Mineiro de Avaliação da Educação Pública - Simave. 2011. Dissertação (Mestrado Profissional em Educação Matemática) - Universidade Federal de Juiz de Fora, Juiz de Fora, MG, 2011.

SOARES, S. Avaliação Educacional como instrumento pedagógico. Trabalho e Sociedade, Rio de Janeiro, v. 2, n. 4, p. 23-25, ago. 2002.

SOUSA, S. M. Z. L.; OLIVEIRA, R. P. D. Sistemas de avaliação educacional no Brasil: características, tendências e uso dos resultados. São Paulo: USP/ FE/CEPPPE, 2007.

SPRINGER, M. G.; BALLOU, D.; PENG, X. Impact of the teacher advancement Program on student test score gains: findings from an independent appraisal. Nashville, TN: National Center on Performance Incentives, 2008. (Working Paper 2008-19).

SPRINGER, M. O. (Ed.) Performance incentives: their growing impact on american k-12 education. Wadhington, DC: Brooking Institution, 2009. 336 p.

SPRINGER, M. G. et al. Teacher pay for performance: experimental evidence from the project on incentives in teaching. Nashville,TN: National Center on Performance Initiative, 2010.

WINTERS, M. A. R. et al. The impact of performance pay for public school teachers: theory and evidence. Harvard University, 2008. (PEPG 08-15).

\section{NIGEL BROOKE}

Professor convidado do Grupo de Avaliação e Medidas Educacionais da Faculdade de Educação da Universidade Federal de Minas Gerais (Game/FaE/UFMG), Belo Horizonte (MG) n.brooke@terra.com.br 